\title{
LOS PELIGROS DE SER MUJER, PERIODISTA Y/O DEFENSORA DE LOS DERECHOS HUMANOS EN EL MÉXICO GLOBALIZADO ACTUAL
}

\author{
Guadalupe Pérez-Anzaldo
}

\begin{abstract}
RESUMEN
El ambiente bélico que ha predominado en los últimos años en México ha deteriorado la percepción que internacionalmente se tiene del país. Las muertes a causa de la guerra oficial desatada en contra de los cárteles mexicanos de la droga han sido más de 50,000 y el número continúa incrementándose diariamente. En especial, las mujeres periodistas y activistas sociales se han visto afectadas por este agravado entorno social; dado que no sólo enfrentan la enquistada violencia de género, sino también la generada tanto por el Estado como por el crimen organizado. En este ensayo, se analizarán los trabajos periodísticos de tres destacadas comunicadoras mexicanas, Lydia Cacho, Carmen Aristegui y Anabel Hernández, quienes a pesar de los amagos en su contra han destacado como líderes de opinión y como luchadoras por la defensa de las libertades y los derechos humanos de los sujetos marginados.

Palabras clave: violencia, periodistas, narcotráfico, globalización, miedo.
\end{abstract}

\begin{abstract}
The war climate that has prevailed in recent years in Mexico has damaged the international perception of the country. The deaths triggered by the official war against the Mexican drug cartels have been more than 50,000 and the number continues to increase daily. In particular, women journalists and human rights activists have been affected by this socially aggravated environment. Not only do they suffer from the entrenched gender violence, but also violence generated by both the State and organized crime. In this essay I will analyze work published by three distinguished and talented Mexican journalists: Lydia Cacho, Carmen Aristegui and Anabel Hernández, who, in spite of the menaces against them, have emerged as leaders of opinion and as well as being advocated activists to the defense of the freedoms and human rights of marginalized subjects.
\end{abstract}

Key words: violence, journalists, drugs, globalization, fear.

La práctica de la violencia, como toda acción, cambia al mundo, pero el cambio más probable es un mundo más violento.

Hannah Arendt (1969: 80)

Dra. Guadalupe Pérez-Alzando. Assistant Profesor of Spanish Department of Romance Languages \& Literatures Universidad de Missouri-Columbia.

Correo electrónico: perezgu@missouri.edu

Recepción: 01- 02- 2012

Aceptación: 06- 03- 2012 
La situación de inseguridad e inestabilidad política y social que se vive en México ha cobrado gran relevancia en los medios de comunicación alrededor del planeta. Indudablemente, las noticias que globalmente predominan sobre dicho país se enfocan en la guerra oficial desatada a partir del 2006 en contra del narcotráfico, así como en su impacto sociopolítico, económico y cultural. Las cifras de homicidios y desapariciones de personas se han disparado hasta rebasar las 50,000 víctimas y estas continúan acumulándose diariamente. En este clima bélico, llama la atención la violencia dirigida hacia quienes ejercen la labor periodística, la cual ha propiciado que de un total de 179 posiciones, se sitúe a México en la 149, de acuerdo con el último informe sobre la Clasificación Mundial de la Libertad de Prensa de Reporters Without Borders.

La impunidad imperante, de acuerdo con dicho informe, ha impedido revertir la cultura de la endémica violencia que se encuentra tan arraigada en el país (Reporters Without Borders 2012). En especial, las mujeres periodistas y activistas sociales se han visto afectadas por este agravado entorno social; dado que no sólo enfrentan la enquistada violencia de género, sino también la generada tanto por el Estado como por el crimen organizado. En este estudio, se analizarán los trabajos periodísticos de tres destacadas comunicadoras mexicanas, Lydia Cacho, Carmen Aristegui y Anabel Hernández, quienes a pesar de los amagos en su contra han destacado como líderes de opinión y como luchadoras por la defensa de las libertades y los derechos humanos de los sujetos marginados.

A pesar de los logros conquistados por las(os) activistas sociales en materia de derechos y libertades civiles para la mujer en México, es evidente que aún predominan las relaciones asimétricas de poder que privilegian al hombre. Los medios masivos de comunicación electrónicos -mediante la continua proyección/divulgación de telenovelas, películas y programas carentes de un contenido educativo y crítico- han jugado un papel vital en la degeneración, reforzamiento y propagación de los roles tradicionales asignados a la mujer en esta sociedad eminentemente patriarcal. Es común, por ejemplo, que en la televisión se proyecten programas donde a la mujer se le objetiviza y victimiza logrando con ello que la gente internalice y perciba la violencia genérica perpetrada hacia ella como algo normal y aceptable. Esto ejemplifica, como ha argumentado Michel Wieviorka, cómo los medios masivos de comunicación han ayudado a fomentar una "aculturación" o "incubación cultural" de la violencia. Es decir, las imágenes de actos crueles e inhumanos que cotidianamente se representan y reproducen en la pantalla logran insensibilizar a una audiencia acostumbrada a trivializarlos. Es precisamente a través de la repetida divulgación de tales imágenes que se forman personalidades insensibles e incapaces de discernir entre la fantasía y la realidad, lo que es moralmente aceptable y lo que no es (Wieviorka 2009: 79). De ahí que el castigo físico -mediante el empobrecimiento, la enfermedad, la mutilación e inclusive la muerte- sufrido por las figuras femeninas que no se ajustan al "Deber ser" impuesto por la normatividad, sea percibido como un bien necesario para resguardar el orden social.

A nivel internacional, los organismos en defensa de los derechos humanos se han pronunciado para que las autoridades mexicanas reconozcan e intenten erradicar el alto grado de violencia genérica que impera en el país. La Comisión Interamericana de Derechos Humanos, por ejemplo, documentó un total de 846 feminicidios en Ciudad de Juárez a partir de 1993 hasta mediados del 2010. De esos casos, 285 ocurrieron en un período de 10 años (de 1993 a 2002). Sin embargo, resulta aún más alarmante que en un lapso de sólo cinco años (de 2005 a 2010) se registraron 922 muertes en el Estado de México sin que hasta ahora el Sistema Nacional para Prevenir, Atender, Sancionar y Erradicar la Violencia contra las Mujeres reconozca las inquietantes cifras en relación con la violencia de género en esa entidad federativa. (Brito 2012). 
Por otro lado y en relación con la violencia de Estado, es importante destacar que existen diferentes mecanismos de control usados con el fin de asegurar la perpetuación de los grupos hegemónicos dentro de las naciones-estado. Como observa Arturo Aldama (2003), es través de la propagación y subsecuente internalización del miedo que estos grupos han ejercido el control, manipulación y sumisión de la gente en un sistema burgués, patriarcal y capitalista globalizado; así como también han intentado disminuir al máximo posible al sujeto marginal u "otro" que no se apega fácilmente al orden social y cultural impuesto por sus aparatos de control. Es precisamente con la diseminación del sentimiento de miedo entre la población civil que el Estado logra alienar a los individuos:

\footnotetext{
As we begin this new millennium, Western nation-states attempt to seduce subject citizens into believing that we live in a borderless cyber "utopia," a cosmopolitan free market of e-commerce and anonymity. The cyber consumers and fantasists in the "fearless" cyber world continue the false magic of global capitalism, further marking the distance between elite consumers and hyperexploited producers of goods. The simulacrum of e-commerce masks the multidirectional movements of "free market" manifest destiny and depends on the learned fetishes for material commodities. (Aldama 2003: 4)
}

La única posibilidad que tiene cada sujeto en contra de este recurso del capitalismo neocolonial, de acuerdo con Aldama, es la formación de alianzas que rebasen límites tanto étnicos como nacionales para confrontar su miedo y oponerse conjuntamente a la violencia ejercida en su contra.

En el caso específico de México, el cerrado control estatal de los medios tanto impresos como electrónicos entorpece significativamente la libertad y flujo de información que recibe la sociedad mexicana. Lo anterior sobre todo después de la firma, el 24 de marzo de 2011, del Acuerdo para la Cobertura Informativa de la Violencia, según el cual la prensa mexicana se compromete a alinearse a la política de Estado homogeneizando la información proyectada en torno a la narcoviolencia generada en el país. La limitación, desinformación y manipulación de las noticias que se difunden en los medios son algunos de los efectivos mecanismos usados por el Estado para alienar y controlar a la población civil en general. De ahí que aquellos medios que no se apegan a los dictámenes gubernamentales sufran persistentemente del acoso y la censura, como es el caso de dos de las escasas revistas que manejan un discurso ideológico disidente al oficial, Proceso y Contralínea (Díaz 2011). Lo anterior ha sido ya documentado y avalado tanto por la Oficina de la Alta Comisionada de Naciones Unidas para los Derechos Humanos (OACNUDH), como por la Organización de Defensa de la Libertad de Expresión, Artículo 19.

Es justo, en este ambiente de zozobra y temor constante que se vive en México, que tres destacadas figuras públicas, Cacho, Aristegui y Hernández, hayan destacado como líderes de opinión y como luchadoras incansables por la defensa de las personas más vulnerables. El trabajo investigativo y el activismo de Lydia Cacho, en particular, se han enfocado en la denuncia y prevención de la violencia genérica. En sus inicios como reportera, ella misma fue víctima de una golpiza y violación sexual por parte de un desconocido que presumiblemente la atacó como un acto de silenciamiento. El estupro sufrido contra su persona, sin embargo, no la amedrentó en lo absoluto sino que, por el contrario, la fortaleció e impulsó a solidarizarse con otras mujeres que, como ella, habían sufrido de acoso, maltrato físico y violación; de ahí que abriera un centro de ayuda para ellas. Su compromiso la llevó, incluso, a iniciar la indagatoria sobre el abuso de menores y la pornografía infantil; lo que conllevó a la publicación de su libro Los demonios del Edén (2005).

Fue precisamente este libro, en el cual se revela el involucramiento de reconocidas figuras públicas -en especial se menciona al poderoso empresario de la mezclilla Kamel 
Nacif Borge- en el negocio de explotación sexual de menores, lo que le ocasionó que fuera encarcelada por órdenes del gobernador de Puebla, Mario Marín, privándosele de sus garantías individuales. Las vejaciones ordenadas contra Cacho, así como la corrupción de las autoridades y la impunidad que aún perdura en México, quedaron en evidencia tras la arbitraria aprehensión de la prestigiosa periodista gracias al apoyo que recibió de distintas organizaciones mundiales, principalmente de Amnistía Internacional. Esta cruda experiencia vivida en carne propia por la periodista mexicana es expuesta en su libro Lydia Cacho, Memorias de una infamia (2007), el cual es testimonio de los peligros enfrentados por las profesionistas que, como ella, desentrañan los mecanismos usados por los poderosos para acallar y encubrir verdades incómodas. Además, en la segunda edición (2006) de su libro Los demonios del Edén, Cacho le añade un prefacio donde reflexiona lo siguiente:

\begin{abstract}
Hace no muchos años el comportamiento del gobierno de Puebla y el uso descarado de la justicia por parte de los poderosos no habría generado mayor sorpresa. En esta ocasión, en cambio, la respuesta resultó abrumadora. Organizaciones internacionales y nacionales de derechos humanos y del derecho a la información se expresaron a favor de mi caso (Amnistía Internacional, el CPJ de Nueva York, la Comisión de Derechos Humanos, la Organización Mundial contra la Tortura, la Sociedad Interamericana de Prensa, entre otras muchas). Muchas ONG en México y el mundo, la Cámara de Diputados, el gobierno de Quintana Roo, los noticieros y diarios prácticamente de todo el país, cientos de colegas y amistades, una docena de articulistas nacionales... Dos países me ofrecieron asilo político e incluso senadoras y políticos priístas rechazaron el proceder del gobernador Mario Marín. (Cacho 2007: 12)
\end{abstract}

Es decir, que de alguna manera la respuesta "abrumadora" a la cual se refiere Cacho, se originó a raíz de su condición como acreditada comunicadora, pero sobre todo a la movilización suscitada en instituciones internacionales enfocadas en la defensa de los derechos humanos. Ante el permanente abuso de autoridad en un país donde se protege a los que tienen el poder político y económico, la única viabilidad a imputaciones como las hechas por dicha periodista es a través de la divulgación y apoyo del gremio de los(as) periodistas y activistas que trabaja y actúa a nivel global.

Lo interesante de la investigación de Lydia Cacho en relación con la compleja red de pornografía infantil es, precisamente, la revelación de las ramificaciones e intersecciones a nivel mundial que tiene este redituable negocio. Como se expone en Los demonios del Edén, en el caso de Jean Touma Hanna Succar Kuri, por ejemplo, él se valía de la necesidad económica de las(os) niñas(os) que conocía para iniciarlas(los) y prostituirlas(los) con clientes nacionales e internacionales que recibían la propaganda tanto en las calles de Cancún como a través del Internet. Sus frecuentes viajes a los Estados Unidos, donde vivía con su esposa y cómplice Gloria Pita Rodríguez, así como sus propiedades en dicho país pusieron en evidencia la facilidad con la que se erosionan las fronteras geográficas-nacionales cuando se trata de la explotación, tráfico y comercialización de menores. Esto último lo demuestra Cacho en su libro más reciente Esclavas del poder (2010); ya que, después de viajar a tan variados países como Turquía, Camboya, Tailandia, Birmania, Japón, Argentina, Israel y Palestina, entre otros, comprueba que la trata sexual de niñas y mujeres está inmersa en una intrincada cadena formada por diversos criminales, incluyendo aquellos de cuello blanco que no sólo permiten, sino que además avalan el lavado de dinero. Cacho explica cómo opera esta red criminal con las siguientes palabras:

Mafiosos, políticos, militares, empresarios, industriales, líderes religiosos, banqueros, policías, jueces, sicarios y hombres comunes conforman una enorme cadena en el mapa internacional del crimen organizado que ha existido durante siglos. La diferencia entre los delincuentes solitarios, o pequeños 


\begin{abstract}
grupos de bandas locales, y las redes criminales globalizadas radica en las estrategias, los códigos y la mercadotecnia. Sin duda alguna, su poder y su esencia estriban en la capacidad de corrupción que las mafias tienen para generar poder económico y político en todas las ciudades en las que conducen sus negocios. El lazo vital que les une es la búsqueda del placer para disfrutar el resultado de su enriquecimiento y empoderamiento. Unos crean el mercado de la esclavitud humana, otro lo protegen, lo promueven, lo alimentan, y otros más renuevan la demanda de la materia prima (Cacho 2010: 14)
\end{abstract}

Los nexos entre los múltiples sujetos principalmente masculinos que operan en esta industria globalizada son clara evidencia del sistema jerarquizado de poder que mantiene en una posición marginal a la mujer. La explotación sexual de la mujer representa, por consiguiente, una forma de esclavitud que además la deshumaniza o cosifica en la sociedad patriarcal. De ahí el interés de Cacho por socavar los artificios culturales y denunciar los abusos físicos y psicológicos contra las mujeres en una sociedad que privilegia al hombre. La encarcelación, el acoso, la tortura, la persecución, las mentiras elaboradas para desprestigiarla y las reiteradas amenazas de muerte son algunos de los peligros que ella ha tenido que enfrentar y sortear, pero lejos de amedrentarse no sólo ha mantenido un discurso ideológico contestatario en su labor periodística, sino que ha continuado su compromiso de ayudar a las personas víctimas de la violencia. Es por esta razón que además de dirigir el centro de ayuda para mujeres que han sufrido de abuso, publicó un "Manual para prevenir, entender y sanar el abuso sexual", Con mi hijo no (2008), para educar y prevenir el abuso infantil.

En lo referente a Carmen Aristegui, su trabajo se ha enfocado en los medios electrónicos, tales como la radio y la televisión, aunque también es columnista en el periódico Reforma. Asimismo, ha publicado algunos libros de entrevistas e investigación como el titulado Uno de Dos (2006) con entrevistas a los principales candidatos, Felipe Calderón Hinojosa y Andrés Manuel López Obrador, durante la contienda electoral hacia la presidencia de la República. Cabe resaltar que su voluntad de transformar el corrupto sistema político mexicano la lleva a publicar, en conjunto con Ricardo Trabulsi, Transición. Conversaciones y retratos de lo que se hizo y se dejó de hacer por la democracia en México (2009), donde se analizan diversas propuestas de líderes políticos y de opinión, quienes han formado una parte decisiva en el desarrollo de la historia contemporánea del país. De la misma manera, su libro dedicado a la denuncia de la pederastia ejercida por un encumbrado líder religioso, Marcial Maciel. Historia de un criminal (2010), es una muestra de su compromiso con las causas sociales que pocos comunicadores en México llevan a cabo, quizás por el bien fundado temor a las represalias provenientes del crimen organizado y/o del Estado, o bien por simple apatía.

Aristegui ha logrado el reconocimiento internacional a su labor periodística gracias a la seriedad y profesionalismo con la que ha abordado temas tan variados como: la violación y muerte de la indígena veracruzana Ernestina Ascensión Rosario a manos de varios miembros del ejército mexicano, la encarcelación arbitraria y las vejaciones sufridas por la periodista Lydia Cacho a manos de las autoridades poblanas, la pederastia de Marcial Maciel encubierta por la Iglesia Católica, la crítica en contra de la Ley Televisa que favorece a los poderosos consorcios Televisa y TV Azteca, así como la relación del cuñado incómodo de Felipe Calderón con el grupo Prisa (este último propietario del periódico español El País) y el conflicto de intereses que a esta empresa y a Televisa le ocasionan los comentarios críticos de la periodista, entre muchos otros. Su capacidad para analizar y exponer la corrupción empresarial, estatal y religiosa la ha llevado a experimentar la violencia ejercida por las compañías afectadas y, en especial, la violencia de Estado desplegada mediante el constante hostigamiento mediático, la represión, el silenciamiento y la censura. Prueba de lo anterior es su despido de la W Radio el 8 
de enero de 2008, puesto que, como afirma Aristegui en una entrevista exclusiva que concedió a la revista Proceso, "Todo parece indicar que hay quien pidió mi cabeza y hay quien la cedió. Hay autores materiales y autores intelectuales en esta historia" (Villamil 2008: 6). De acuerdo con dicha entrevista, ella ahonda en el tema de la manera siguiente: "[L]os "autores intelectuales" del silenciamiento de su espacio informativo son directivos de Televisa, integrantes del Consejo Mexicano de Hombres de Negocios, concesionarios descontentos con su actitud ante la reforma electoral y funcionarios de Comunicación de Los Pinos, desde donde se le hizo saber que su noticiario "no era deseable para la Presidencia de la República" (Villamil 2008: 6-7).

Otro ejemplo de la manipulación mediática en contra de la comunicadora es el caso de la entrevista que le hiciera a Miguel de la Madrid, donde el anciano ex presidente mexicano reconoció que se había equivocado al nombrar a Carlos Salinas de Gortari como su sucesor. Inmediatamente después de que De la Madrid acusara de manera directa a la familia Salinas de ser corrupta y de tener vínculos con el narcotráfico, Salinas de Gortari le dirigió a la periodista una carta en la que descalificaba a De la Madrid como informador fiable por cuestiones de edad -a quien posteriormente se le obligó a retractarse de sus declaraciones- mientras que a Carmen Aristegui la acusó de haber "abusado de la confianza" del ex mandatario por haberlo expuesto "en su delicada circunstancia". Es decir, los esfuerzos de Salinas de Gortari estuvieron dirigidos a desprestigiar a Aristegui por supuestamente haber forzado una entrevista con una fuente poco creíble y haber tergiversado lo referido por su entrevistado. Imputaciones que ella acertadamente supo rebatir y que, en lugar de empañar su imagen de periodista comprometida con la verdad, la fortalecieron.

El segundo despido de Aristegui ocurrió el 7 de febrero de 2011, esta vez de la compañía propiedad del grupo MVS donde había sido contratada dos años antes, con imputaciones de haber violado el "código de ética" de dicha empresa. Este pretexto, sin embargo, resultó fallido toda vez que la opinión generalizada señaló como verdadera causa la posición crítica tomada por la audaz periodista quien, en referencia a una manta desplegada en la Cámara de Diputados por el diputado petista Gerardo Fernández Noroña, ella formulara la siguiente pregunta al aire: “Tiene o no problemas de alcoholismo el presidente de la República?”. Lo trascendental de este caso en particular es la respuesta masiva y global en apoyo a Carmen Aristegui:

\footnotetext{
En menos de 48 horas, el tema del despido de la periodista y su equipo se convirtió en hashtag (tema de moda en todo el mundo) en Twitter y decenas de miles de participantes de Facebook se sumaron al grupo “Apoyo a Carmen Aristegui”. Más de $80 \%$ de los mensajes atribuían su salida a presiones de Los Pinos y no a una presunta violación al código de ética [...] A pesar de ser un día feriado, el lunes 7 poco más de 200 personas se reunieron frente a las instalaciones de MVS Radio para gritar “¡Carmen sí, Felipe no!” y a exigir la pronta reinstalación de la periodista. La frase de un cartelón se replicó en todas las redes sociales: “Extra, extra. Borracho atropella a periodista Aristegui!”. (Villamil 2011a: 12)
}

Las evidentes, pero negadas presiones oficiales para que el grupo MVS despidiera a esta osada comunicadora fueron infructuosas debido a la creciente concientización de gente dentro del país que demanda un alto al silenciamiento e intolerancia oficial hacia las voces críticas como la de Aristegui, así como al apoyo internacional hacia los periodistas comprometidos socialmente como ella. A pesar de la abundante animosidad oficial en su contra, Carmen Aristegui continúa teniendo un alto rating de audiencia radiofónica y el programa de análisis que conduce en la cadena CNN en español es visto por un público cada vez más numeroso deseoso de recibir información veraz y objetiva.

Por otro lado, la periodista Anabel Hernández, quien colabora para el sitio en Internet Reporte Índigo, sabe también lo que significa ser acorralada hasta el extremo de temer por 
su vida y, por lo mismo, tener que estar siempre custodiada por dos guardaespaldas que no la pierden de vista ni un solo momento. Las amenazas de muerte se produjeron a raíz de la publicación de su libro Los señores del narco (2010), en el cual Hernández evidencia los nexos del actual secretario de Seguridad Pública Federal, Genaro García Luna, con el narcotráfico. No obstante, el que este sea el personaje a quien ella atribuye la violencia en su contra, no se ha hecho nada por dar seguimiento a sus denuncias. Resulta sobre todo alarmante el hecho de que la mayoría de sus colegas periodistas se han negado a difundir los llamados de Hernández para que se investigue a ese funcionario público, apegados al Acuerdo para la Cobertura Informativa de la Violencia firmado por los medios para los que trabajan. La conferencia que Hernández presentó en mayo del 2011 en el Foro Impunidad como Limitante de la Libertad de Prensa no recibió la atención mediática que ella esperaba. Irónicamente, como refiere Miguel Ángel Granados Chapa, uno de los criterios editoriales del señalado acuerdo establece que debe imperar la solidaridad "ante cualquier amenaza o acción contra reporteros o medios" (2011: 1).

El mismo silencio mediático prevaleció en torno a las acusaciones dirigidas al ex presidente Vicente Fox Quezada que, de acuerdo con la información que le proporcionó un agente de la DEA en el 2006, estuvo involucrado en la fuga del capo mexicano conocido como El Chapo:

El agente me confió que informantes de la DEA infiltrados en la organización de Ignacio Coronel Villarreal le aseguraron que Guzmán Loera salió del penal de Puente Grande luego de pagar una suma millonaria de dólares como soborno a la familia del presidente Vicente Fox. Y que el acuerdo incluía la protección sistémica del gobierno federal a él y su grupo: la todopoderosa organización del Pacífico. Actualmente Vicente Fox es uno de los principales promotores de la legalización no sólo del consumo de todas las drogas, sino de su producción, distribución y comercialización. (Hernández 2010:14)

En relación con la globalización, es importante mencionar que la censura no se limita a las fronteras nacionales, por el contrario, los tentáculos del poder se extienden a otros espacios geográficos cuando se trata de resguardar una imagen oficial cada vez más quebrantada y empañada en todo el mundo. Tal como sucedió en el caso de la revista francesa L'Express que fue criticada enfáticamente por el embajador de México en Francia, Carlos de Icaza, por haber publicado una entrevista que la periodista Léonore Mahieux le hizo a su colega mexicana Anabel Hernández en relación con la publicación de su libro Los señores del narco (Villamil 2011a: 10). A pesar del intento de acallar el discurso beligerante de Hernández, igual que les sucede a Lydia Cacho y Carmen Aristegui, ella no ha claudicado a su búsqueda de la verdad.

Afortunadamente, ninguna de las periodistas aquí presentadas ha sufrido el trágico fin de sus colegas femeninas como María Elizabeth Macías, quien se hacía llamar "La Nena de Nuevo Laredo" y cuyo cadáver fuera abandonado junto a partes de computadora y una nota que atribuía su muerte a los reportes sobre el narcotráfico que ella acostumbrara publicar en el Internet. Es loable la labor profesional de mujeres fuertes y creadoras como Lydia Cacho, Carmen Aristegui y Anabel Hernández, que ante las amenazas, vituperios y atentados en contra de su integridad física anteponen su interés por cambiar las injustas condiciones de vida de la población mexicana en general. Dentro del periodismo internacional, la situación de los medios mexicanos está bajo escrutinio mundial por el alto índice de asesinatos en contra de los periodistas y, ante esta situación, los logros conseguidos por estas tres destacadas comunicadoras muestran la importancia de crear propuestas críticas válidas así como una prensa comprometida con la sociedad. 


\section{Bibliografía}

Aldama, Arturo J. (Ed.). 2003. Violence and the Body: Race, Gender, and the State. Bloomington, IN: Indiana University Press.

Arendt, Hannah. 1969. On Violence. New York: Harcourt Brace.

Aristegui, Carmen y Ricardo Trabulsi. 2009. Transición. Conversaciones y retratos de lo que se hizo y se dejó de hacer por la democracia en México. México, D.F.: Grijalbo.

Brito, Luis. 2011. "Feminicidios en el Estado de México, tarea pendiente". CNN.mx. 01/02. http://mexico.cnn.com/. Consulta: 27 de enero de 2012.

Cacho, Lydia. 2006. Los demonios del Edén. El poder que protege a la pornografía infantil. ( $2^{\mathrm{a}}$ ed.). México, D.F.: Grijalbo, Actualidad.

2007. Memorias de una infamia. México, D.F.: Grijalbo.

2008. Con mi hijo no. Manual para prevenir, entender y sanar el abuso sexual. México, D.F.: Grijalbo.

2010. Esclavas del poder. Un viaje al corazón de la trata sexual de mujeres y niñas en el mundo. México, D.F.: Grijalbo.

Campbell, Monica. 2008. "Battling the Demons of Eden". Amnesty International Magazine. Fall 2008: 10-13.

Díaz, Gloria Leticia. 2011. "Informes de ONU y CIDH incluyen agravios del gobierno contra Proceso". Proceso.com.mx. 24/10. http://www.proceso.com.mx/. Consulta: 26 de enero de 2012.

Granados Chapa, Miguel Ángel. 2011. “Anabel Hernández y Genaro García Luna”. Proceso. com.mx. 09/05. http://www.proceso.com.mx/. Consulta: 27 de enero de 2012.

Hernández, Anabel. 2010. Los señores del narco. Mexico D.F.: Grijalbo.

Lovera, Sara. 2011. "Mujeres periodistas en riesgo". Proceso.com.mx. 29/01. http://www. proceso.com.mx/. Consulta: 27 de enero de 2012.

Reporteros sin Fronteras. 09/2011. "México". Informe mundial. http://es.rsf.org/reportmexico,184.html. Consulta: 26 de enero de 2012.

2012. “Press Freedom Index 2011-2012”. 25/01. http://en.rsf.org/IMG/CLASSEMENT_ 2012/C_GENERAL_ANG.pdf. Consulta: 26 de enero de 2012. 
PÉREZ-ANZALDO: Los peligros de ser mujer, periodista y/o defensora de los derechos humanos...

Vértiz de la Fuente, Columba. 2012. "Las telenovelas, factor de atraso: Epigmenio Ibarra". Proceso.com.mx. http://www.proceso.com.mx/. 25/04. Consulta: 27 de enero de 2012.

Villamil, Jenaro. 2008. "El acoso, las presiones, el silenciamiento". Proceso. 13/01: 6-12. 2011a. "Caso Aristegui: los intereses en juego". Proceso. 13/02: 6-15.

2011b. "Intolerancia ante la prensa crítica". Proceso. 13/02: 10-11.

Wieviorka, Michel. 2009. Violence. A New Approach. David Macey trans. London: Sage. 
